\title{
OS SENTIMENTOS GERADOS NOS (AS) PROFISSIONAIS ENFERMEIROS (AS) DIANTE O PROCESSO MORTE/ MORRER DO PACIENTE
}

\author{
Larissa de Carvalho Silveira*, Maiara Brandão de Brito*, Sandra Dutra Cabral Portella** \\ Autor correspondente: Maiara Brandão de Brito - mainn_b@hotmail.com \\ * Discentes do $8^{\circ}$ semestre do curso de Enfermagem da Escola Bahiana de Medicina e Saúde Pública - EBMSP. \\ ** Docente do curso de Enfermagem da Escola Bahiana de Medicina e Saúde Pública - EBMSP.
}

\begin{abstract}
Resumo
As atitudes de negação da finitude humana na sociedade ocidental atualmente constituem-se como reflexo de uma construção sociocultural e histórica. A influência cultural e a visão de uma enfermagem curativista dificultam a elaboração do luto durante o enfrentamento da morte do paciente provocando nos enfermeiros(as) sentimentos de fracasso, incapacidade e incompetência. $O$ trabaIho desenvolvido pela enfermagem revela-se cansativo desgastante, devido a convivência com a dor, sofrimento e morte dos clientes. Tais questões contribuem para o desgaste emocional - provocando o estresse. Desgaste no humor e desmotivação acompanhado de sintomas físicos e psíquicos acarretam um processo gradual para o agravamento do estresse entre outros sentimentos que podem evoluir para um desgaste emocional crônico, a Síndrome de Burnout. Este estudo tem por objetivo analisar as produções científicas que abordam os sentimentos gerados nos enfermeiros (as) durante o processo morte/morrer do paciente. Trata-se de uma pesquisa do tipo revisão integrativa de caráter exploratório. Os artigos analisados encontram-se indexados nas bases de dados do Sciello e Lilacs. O período de estudo circunscreveu entre os anos 2001 a 2011. Os principais achados deste estudo possibilitaram uma análise sobre a produção científica em seis categorias: negação da morte e os sentimentos em relação ao fim da vida, desconforto durante o preparo do corpo, relação dos avanços tecnológicos com a obstinação terapêutica, dor incontrolável do paciente, despreparo do enfermeiro no enfrentamento da morte e sofrimento psíquico. Constatou-se que o despreparo do enfermeiro (a) reflete em um cuidado deficitário que gera situações (des)humanas e prejudiciais ao cuidado humano no fim da vida, revelando-se um "descuidado" do profissional que cuida.

Palavras-chave: Morte; Emoções; Enfermeiros (as).
\end{abstract}

- Artigo submetido para avaliação em 18/09/2013 e aceito para publicação em 11/11/2015 • 


\title{
FEELINGS EXPERIENCED BY PROFESSIONAL NURSES WHEN FACING PATIENTS' DYING PROCESS OR DEATH
}

\begin{abstract}
The denial of human finitude in today's Western society is a reflection of a socio-cultural and historical construction. The cultural influence and the idea of a curative nursing service make the grieving process difficult when facing the death of a patient, causing nurses to experience feelings of failure, powerlessness and incompetence. Once understanding the cure as the only therapeutic option, many of THESE professionals develop psychological distress, among other uncomfortable feelings, which may escalate into a chronic emotional distress, the Burnout Syndrome. This study aims at analyzing the feelings experienced by nurses during the patient's dying process or death. It is an integrative review research of the exploratory kind. The analyzed articles are indexed in Sciello's, Lilacs' and Bireme's databases. The study period covers the years from 2001 through 2011. This study's main findings allowed researchers to establish an analysis about scientific production in six categories: death denial and feelings related to life termination, discomfort during body preparation, a list of technological breakthroughs in therapeutic obstination, patient's uncontrollable pain, the unpreparedness of nurses when facing death and psychological distress. It was concluded that nurses' unpreparedness reflects a poor care service that produces inhumane situations, detrimental to human treatment at the end of life, which reveals to be a health care professional carelessness.
\end{abstract}

Keywords: Death; Emotions; Nurses.

\section{INTRODUÇÃO}

A morte na atualidade é algo que as pessoas tentam fugir, evitar, a fim de não ter de enfrentá-la, não encará-la. Deixou de ser "doméstica" e passou a ser "hospitalizada". Portanto, fica explícita a dificuldade de enfrentamento da morte pelas civilizações pós-modernas, impedindo que os indivíduos criem maneiras de compreender as perdas e a própria finitude.

Os estudos científicos, acerca da morte a definem como a parada das funções vitais e a separação do corpo e da alma. $\mathrm{Na}$ atualidade, o critério comumente utilizado é uma avaliação da função cerebral. Embora a terminalidade humana seja uma certeza conhecida por todos os indivíduos, ainda se constitui como um tabu social de forma a comprometer o enfrentamento da mesma. ${ }^{(1)}$
A importância do histórico social da morte/morrer oferece sentido às formas de posicionamento das culturas face à questão da morte, estando esta impregnada de significados e valores que variam a depender do período e do espaço cultural.

As atitudes e os rituais diante da morte têm se modificado ao longo dos tempos e de acordo com cada cultura, conforme a convivência mantida entre os homens, variando a partir do seu apego a bens, crenças e valores cristalizados como também dogmas indiscutíveis e a religião na qual estão inseridos. ${ }^{(2)}$

No que diz respeito ao ambiente de trabalho "força" o contato frequente dos (as) enfermeiros (as) com a experiência da morte, no entanto não isenta tal profissional do sentimento de impotên- 
cia e vazio interacional diante das perdas e da compreensão das mesmas. Tendo em vista que cresceram tendo como visão de morte a assustadora caveira dos desenhos animados e a lembrança de cerimônias fúnebres como eventos proibidos para crianças. Essas crianças cresceram e escolheram como profissão a enfermagem que tem como função principal o cuidado holístico e integral, o que se subtende como um processo que ocorre até o fim da vida. Mesmo com essa incumbência, assuntos relacionados às perdas são considerados por muitos como aspectos de abordagem deficitária durante a formação profissional que é, em sua maioria, voltada a aceitar a cura como única opção terapêutica e deixam de elucidar as questões do luto como um processo único e não um protocolo repleto de regras inquebráveis.

O trabalho desenvolvido pela enfermagem tem se revelado desgastante, visto que o frequente contato com o sofrimento humano e a morte, a necessidade de abordar e cuidar do paciente e sua família dentro deste contexto, assim como habilidade suficiente para intervir em situações adversas, coordenar a equipe de enfermagem, entre outros fatores do dia-a-dia laboral destes profissionais, se revelam como questões que contribuem para o desgaste emocional - provocando o estresse.

Assim, a impotência demonstrada pelos profissionais de não poder "dominar a morte" e/ou a dificuldade pessoal de aceitar a terminalidade como parte da vida, acaba ocasionando o sentimento de impotência e frustração que a longo prazo evoluem para o cansaço emocional que é considerado o traço inicial do processo de estresse e outras síndromes.

De um modo em geral, não há espaço para a morte em nossa sociedade. Enfrentá-la, embora seja uma constante, causa no profissional enfermeiro (a) uma sobrecarga da função, justificada pelo fato da morte ser um dos principais motivos da angústia humana, o que traz à tona sua vulnerabilidade diante a vida. ${ }^{(6)}$

Além disso, o processo cultural interfere também na deficitária abordagem da morte durante a graduação, refletindo em profissionais despreparados e inseguros para ofertar um cuidado ao paciente até o fim da vida.

A dificuldade em enfrentar a morte/morrer é quase que inevitável, principalmente quando a experiência é com a morte do "outro" que se cuida, juntamente com o acompanhamento algumas vezes da fase terminal e a permanência da família frente a esta realidade gerando sentimentos de impotência, desconforto, dor, angústia, cansaço emocional e medo, exigindo extenso esforço psicológico de quem presta assistência ao outro que está morrendo.

Portanto, busca-se saber quais os sentimentos gerados no enfermeiro (a) durante o processo morte/morrer do paciente. Objetivando, portanto, uma análise das produções científicas que abordam estes sentimentos durante o processo.

As contribuições desta pesquisa são de proporções tanto profissional quanto acadêmicas. Em relação a primeira essas reflexões serão pertinentes para discutir a base do preparo do enfermeiro(a) para lidar com a morte e o morrer do outro. No foco das contribuições acadêmicas pode-se inferir o fortalecimento nas instituições de ensino superior sobre a importância das discussões acerca da morte/morrer e estimular discussão a respeito da severidade das consequências patológicas, que podem ser geradas no decorrer da assistência do (a) enfermeiro(a) durante o processo de morte do outro, evitando, assim, difíceis repercussões econômicas e sociais para o profissional.

\section{REFERENCIAL TEÓRICO}

\section{HISTÓRICO DE ENFRENTAMENTO DA MORTE NA SOCIEDADE OCIDENTAL}

A morte deve ser encarada como sendo parte da existência humana, do nascimento, crescimento e desenvolvimento. É uma das poucas coisas de que temos certeza. É parte integral de nossas vidas que 
realça a existência humana. A morte é tão natural e previsível como nascer. É o estágio final do crescimento, é o modo de vida do ser humano e a etapa final do seu desenvolvimento. ${ }^{(9)}$

Porém vale salientar que as questões existenciais embora sejam simples em sua essência refletem questões complexas que envolvem o ser e o estar no mundo. E que este ser está num mundo capitalista, tecnológico e mecanicista voltado para a onipotência e que se orienta para o progresso. $\mathrm{O}$ fim da vida sempre foi detestável para o homem, e provavelmente sempre será. No inconsciente da mente é inconcebível falecer.

A sociedade ocidental tem forte influência da civilização grega e das religiões judaica e cristã. A civilização grega foi o berço do pensamento ocidental. Os principais períodos que influenciaram o enfretamento da morte foram datados entre os séculos V ao XII, também conhecida por Alta Idade Média se caracterizavam por ritos fúnebres domesticados, ou seja, o fim da vida era vivenciado no seio familiar, marcado pelas despedidas e reconciliações. ${ }^{(10)}$

Durante a Alta Idade Média a morte era encarada com mais naturalidade. Havia uma preocupação em deixar tudo organizado na família, como uma espécie de prestação de contas do indivíduo, que, geralmente deixava instruções sobre a disposição de sua alma e bens materiais.

Vale lembrar que no passado as pessoas se preparavam para morrer. E que era considerada boa morte quando não chegava de surpresa para o indivíduo, permitindo-o a preparação do testamento contendo a encomendação de sua alma à Deus e os executores das últimas determinações do testador logo após a confirmação da morte, iniciavam-se as manifestações de luto dos familiares e amigos, que se revelavam das mais variadas formas dramáticas. ${ }^{(1-12)}$

Assim, pode-se constatar que a visão de finitude nesta época estava muito próxima do que se busca nos dias atuais, visto que era encarada como parte do ciclo da vida, sendo vivenciada e assistida por familiares, como ocorre durante o nascimen- to, o início e o fim da vida como um ciclo que se completa.

Estudos durante a alta Idade Média comprovam que a morte súbita era considerada vergonhosa e conclamada como um castigo de Deus, pois inviabilizava a preparação para o morrer. Isso revela uma característica marcante desse período: os mortos eram enterrados em túmulos comunitários, geralmente em igrejas, pois acreditavam que estariam guardados pelos santos e protegidos do inferno. Nessa perspectiva, identifica-se que muitas pessoas não nutriam os atuais sentimentos de medo, negação e resistência a finitude, ao contrário, mortos e vivos dividiam o mesmo espaço, a igreja embora servisse como cemitério era também o local onde ocorriam os cultos religiosos. ${ }^{(10)}$

Porém, durante a baixa Idade Média, a morte passa a ser "clericalizada", o acesso da alma ao paraíso passou a depender da interferência da Igreja e havia a possibilidade de ir ao céu ou inferno a depender das atitudes do indivíduo durante a vida. A partir de então, perdeu-se a confiança em relação às perspectivas sobre o fim da vida e passaram a temer a morte, com toda essa imponderabilidade que se criou para falar e pensar no fim da existência humana. Com isso, as pessoas procuram manter a morte em estado de latência, com vistas a evitar a sensação de angústia que existe em relação à finitude do ser humano. ${ }^{(12)}$

$\mathrm{Na}$ Idade Moderna, a ação do indivíduo perante o fim da existência passou a ser romantizada, considerada cruel a retirada do homem da própria vida. Ocorrendo, a partir disso, a separação entre a vida e a morte e uma marginalização da última. A morte foi afastada do meio social, os cadáveres deixaram de ser enterrados nas igrejas para serem alocados em túmulos, agora individuais, em cemitérios, geralmente afastados da cidade. ${ }^{(10)}$

$\mathrm{Na}$ Bahia ocorreu o movimento que ocorreu na Bahia em 1836, conhecido como a "Cemiterada", uma revolta contra a Lei do Cemitério, que proibia enterros em igrejas e garantia o monopólio de sepultamentos ao cemitério do Campo Santo. O cemitério foi completamente destruído pelos mani- 
festantes, numa revolta incentivada e organizada pela Igreja Católica. ${ }^{(11)}$

No Brasil e na Bahia a cultura era fortemente orientada com vistas à preparação para a morte, sendo marcada por cortejos fúnebres pomposos que revelavam a preocupação com os próprios cadáveres. Os enterros em igrejas eram entendidos como salvação da alma. ${ }^{(11)}$

No Brasil, imediatamente após a confirmação da morte entravam em ação as chamadas "carpideiras" que se revelavam como profissionais que choravam pelos mortos. A situação era considerada na época, normal e necessária, como uma espécie de ritual para afastar os maus espíritos e o próprio morto de perto dos vivos. ${ }^{(13)}$

Assim, o corpo era preparado com o uso da mortalha, como roupa fúnebre; o velório que era representado pela companhia de familiares e amigos ao falecido durante a noite; o sepultamento, as missas oferecidas ao falecido e o cumprimento dos desejos explicitados pelo mesmo em testamento concluíam o ritual fúnebre realizado no Brasil. Após o enterro, buscava-se apagar qualquer vestígio da morte em casa. $\mathrm{Na}$ época, só a família enlutava. ${ }^{(11)}$

As pessoas, em sua existência, percorrem etapas substancialmente constituídas de sentimentos múltiplos e são educadas para a repulsa da morte, buscando afastar-se da finitude. Para tanto, torna-se possível justificar os modos e reações das pessoas quando o assunto é a finitude. Evita-se qualquer tipo de aproximação com a mesma, a começar pela negação da pronúncia da palavra morte até a aceitação da sua presença cotidianamente. Mesmo tendo consciência que a morte está presente em todo o processo de vida e se faz refletir nas perdas mais simples. ${ }^{(14)}$

O enfrentamento da morte é difícil e angustiante para quem a vivencia, podendo ser mais ainda para quem a observa, porque a morte provoca rupturas profundas entre quem morreu e o outro que continua vivendo. Se encarar a morte do outro provoca reflexões sobre a própria morte. Isso somado ao real significado da palavra dicionariza- da, que entre outras descrições refere-se ao "cair no esquecimento", mais as interrogações sobre o pós-morte entre outras dúvidas (in) esclarecíveis e que as idealizações criadas na mente humana são incapazes de suprir, são fatores que agregados ou não geram um desconforto e desprazer, tendo em vista que as atitudes perante o fim da vida estão intimamente ligadas ao modo de ver o mundo e o processo cultural vivenciado por cada um. ${ }^{(15)}$

A morte de alguém querido sempre vem acompanhada de pesar, sofrimento, choros e negação. Por esta dificuldade do homem em encarar a morte como uma parte orgânica, natural e lógica da vida, o processo de morrer envolve vários estágios.

Muitas são as etapas psicológicas ocasionadas na pessoa que se depara com a morte. Sendo essas definidas como: negação, ira, barganha, depressão e aceitação. Interpretadas da seguinte forma: $\mathrm{Ne}$ gação - caracteriza-se pela difícil aceitação de que o fato da morte está para acontecer. A negação admite a esperança de existir; Ira - etapa em que prevalece a raiva, revolta. "Por que eu?". É o questionamento mais frequente; Barganha - fase em que o moribundo faz promessas, acordos com amigos, familiares, profissionais e Deus em troca de mais um tempo de vida; Depressão - no quarto estágio o paciente entende que a morte é inevitável. Seus mecanismos de defesa não são mais eficientes, o indivíduo fecha-se em si e sua angústia é evidente; Aceitação - é uma fase de paz, resignação, onde o paciente tenta dar sentido a vida. É o tempo de rememorar o passado, meditar sobre o futuro, reorganizar os negócios e os familiares. ${ }^{(9)}$

São estágios que não obrigatoriamente seguem uma sequência, e alguns indivíduos não passam por todos eles. É um processo que envolve uma gama de fatores, dentre eles religião, cultura, sociedade, sentimentos e familiares.

Diante das revelações aqui explícitas de alguns estudos sobre o histórico da morte no Brasil, pode-se perceber a influência cultural e religiosa no enfrentamento das perdas e o silenciamento que se revela como traço da inadmissão da dor e da vulnerabilidade diante da finitude. 


\section{ENFERMAGEM: ENFRENTANDO A MORTE NO TRABALHO}

A enfermagem é uma profissão que tem como foco o cuidado humano. $O$ cuidado de enfermagem se apresenta em duas vertentes distintas que se referem aos procedimentos técnicos à sensibilização nas formas de cuidar do outro, traduzindo assim como a essência da profissão. (4)

O profissional de enfermagem deve demonstrar destreza, agilidade, habilidade, bem como, capacidade para estabelecer prioridades e intervir de forma consciente e segura no atendimento ao ser humano, sem esquecer que, o cuidado é o elo de interação/integração/relação entre profissional e cliente. ${ }^{(16)}$

Assim, leva a refletir que o papel da enfermagem ultrapassa o cuidado relacionado à patologia e procedimentos técnicos e incorpora ao seu processo de trabalho o monitoramento dos serviços, práticas educativas, administração de recursos humanos e gestão das unidades assistenciais de saúde. Todo este trabalho é fortemente centrado no cumprimento de normas, protocolos e rotinas que requerem do (a) enfermeiro (a) agilidade e decisões assertivas, capacidade de liderança e criatividade para atender a demanda dos serviços.

A multiplicidade de tarefas que recai sobre os (as) enfermeiros (as) faz com que se confrontem diariamente com processos decisórios que dependem muitas vezes de agilidade e prioridade de ações. A realidade de trabalho vivenciada diariamente pela enfermagem revela-se cansativa e desgastante, devido à convivência com a dor, sofrimento e morte dos clientes. ${ }^{(17-18)}$

Dessa forma, resgatar o humano dentro do processo de morte e do morrer, com vistas ao cuidado biopsicossocial por mais imprescindível que seja não se apresenta como tarefa fácil, visto que a condição de "profissional da saúde", que cuida, não pode ser separada da condição de "ser humano" que está inserido num processo cultural, e, portanto, que se angustia, sofre e sente medo, impotência, ódio, revolta, dor e culpa diante das perdas, pelo simples fato de temer olhar para a própria finitude. Nesse sentido, o significado da morte varia a depender da formação cognitiva, estrutural e religiosa. Na sociedade ocidental, evita-se falar sobre a finitude humana, a morte é um tabu e aos poucos é excluída do meio social. ${ }^{(5)}$

Essa exclusão da morte pela sociedade está impregnada por sinônimos negativos e ao ser mencionada é automaticamente renegada, proibida, desconsiderada. Além disso, o modo misterioso e incerto que caracteriza a morte é o responsável pelo sentimento de negação e medo da finitude. Pois, embora existam inúmeras especulações a respeito da experiência com a morte, sejam embasadas pela religião, cultura ou ciência, não passam de incertezas, pois os que a vivenciaram não puderam compartilhar relatos com os vivos, mantendo o fim da vida na condição de incógnita.

A nova visão do mundo do cuidado é centrada no ser humano passa a exigir dos profissionais de enfermagem não só a competência técnica e o conhecimento específico, como também capacidade de compreender o ser humano como um ser de relações. Para tanto, é necessária uma boa relação com os familiares ocorre se o profissional enfermeiro (a) se mostrar, além de competente, uma pessoa capaz de propagar simpatia, ser comunicativo e sociável, como instrumentos de trabalho para uma prática mais humanizada. ${ }^{(1-19)}$

Os profissionais de enfermagem convivem, diariamente, com pacientes em condições de saúde instáveis. Cuidando dos sintomas e do sofrimento biopsicoespiritual, não só do doente, como também da família. Por muitas vezes, a equipe se depara com um paciente em fase terminal todos aqueles que se encontram em situações em que os recursos terapêuticos vigentes, não representam melhora e há uma tendência do paciente para o êxito letal. Dessa forma, o diálogo entre equipe, familiar e paciente deve ser o principal eixo para o tratamento. ${ }^{(20)}$

A enfermagem recebe treinamento, conhecimento técnico e científico, trabalham em salas com todo tipo de equipamento para a manutenção da 
vida como os desfibriladores, monitores portáteis, gerador de marca passo e respiradores. Todo esse cenário sinalizador de manutenção da vida pode gerar situações de frustração e estresse, principalmente quando o paciente morre. ${ }^{(5)}$

O tratamento do paciente bem sucedido gera prazer nos profissionais de enfermagem, porém quando o processo de morrer é prolongado, devido aos investimentos terapêuticos e ao final termina em morte ocasiona nesses profissionais, desgaste. ${ }^{(21)}$

A morte do paciente ao qual se dedicou horas de trabalho desperta no profissional de enfermagem sentimento de culpa, porém a morte do doente também gera alívio. Assim a posição dos (as) enfermeiros (as) é bastante conflitante, por ficarem em dois pólos: o da onipotência e o da impotência. Os sentimentos gerados pela enfermagem frente a situação de morte/morrer, são geralmente de caráter negativo, como: impotência, medo frustração, silêncio, culpa, irresolução, revolta. Isso nos faz perceber que todo progresso e arsenal tecnológico pode retardar a morte, mas não ensina a compreender os sentimentos gerados por essa perda. Vale lembrar ainda, que o enfoque tecnológico de nossa sociedade provoca uma "coisificação" e despersonalização do viver e do morrer. ${ }^{(22-23)}$

Se considerarmos o ser humano em sua dualidade, corpo e mente, será fácil compreender que o corpo influencia mudanças na mente e estas, por vez, agem sobre o corpo. Diante das formas de enfrentamento da morte na sociedade ocidental e do processo de trabalho dos enfermeiros, é possível constatar que, o enfrentar a morte está repleto de estresse, agitação, frustração e preocupações. Sendo assim, esta é fonte constante de perturbações e doenças psicossomáticas. ${ }^{(24)}$

Em unidades críticas, o processo do morrer é frequente, as experiências são singulares. $O$ enfermeiro, profissional mais presente frente ao processo de cuidar, está, portanto, em maior contato com a morte. Morte de indivíduos com os quais conviveu, por muito ou pouco tempo, com os quais estabeleceu vínculo e afetos. ${ }^{(22)}$
A própria prática curativa da enfermagem leva a uma vivência maior com situações de morte, no entanto, por uma série de variáveis nem sempre o enfermeiro encontra-se preparado para atender as necessidades do paciente em morte iminente. Por outro lado, o cuidado com o corpo no pós-morte não é um momento de prazer para os profissionais. O preparo do corpo de uma pessoa morta traz angústia, medo e certeza de que um dia a morte chegará e gera reflexões sobre a própria terminalidade. ${ }^{(25)}$

O envolvimento com o paciente é um fator considerável na manifestação do sentimento presente nesse momento, sua intensidade varia a depender do vínculo estabelecido durante o processo do cuidar. Por isso, mais uma vez será elucidada a força da questão cultural e religiosa diante das formas de enfrentamento da morte e como essas afetam a compreensão e aceitação frente às questões existenciais. Pois, se morte e vida não fossem vistas pela sociedade como situações opostas e sim, componentes de um mesmo ciclo, a finitude humana seria menos complexa e melhor aceita. ${ }^{(26)}$

A consequência da negação da finitude é que o paciente em morte iminente nem sempre encontra profissionais capazes de ajudá-lo em suas necessidades durante o processo de morrer, que de fato mantenha sua condição humana. O profissional enfermeiro só poderá fazer isso quando enfrentar o próprio medo e desejo de destruição da morte, bem como compenetrar-se das próprias defesas, e considera ainda que estas podem interferir nos cuidados com o paciente. ${ }^{(9)}$

O processo de formação é fator imprescindível no desenvolvimento de competências específicas relacionadas com as perdas e o cuidado no fim da vida. Deve considerar a compreensão da morte como parte do ciclo da vida, evento integrante da mesma e não como algo a ser combatido. Ainda sim, as rotinas ou discussões sobre as melhores formas de organizar os serviços e encará-la não serão insuficientes se não agirmos na formação de quem estará na assistência. Pois, o processo de trabalho da enfermagem acontece através da rela- 
ção estabelecida entre o ser que é cuidado e o cuidador. ${ }^{(27)}$

Portanto, o processo de morrer será construído de forma compartilhada entre seres que se respeitam e irá contar com profissionais devidamente preparados para contribuir para que a finitude de cada paciente seja minimamente dolorosa e altamente humana, colaborando assim, para a construção de um mundo mais solidário. ${ }^{(27)}$

Sem um preparo com relação ás questões da finitude, o esforço diário de enfermeiros frente ao cuidado gera frustração por se sentirem, entre outros fatores, incapazes de driblar a morte. O frequente estado de luto, a fragilidade e o despreparo, quando associados ao estresse que lhe é depositado diante de tais enfrentamentos, tem gerado desgaste emocional, despersonalização e redução da realização profissional.(22)

Mesmo sabendo que o estresse é um fenômeno individual, existe uma ampla variedade de determinantes de estresse, relacionados ao individuo, ao cargo e a organização. Desta forma questões como sobrecarga de atividades e carga emocional, associado ao constante enfrentamento com a morte, gera nos profissionais enfermeiros fatores estressantes. ${ }^{(28)}$

Desgaste no humor e desmotivação acompanhados de sintomas físicos e psíquicos acarreta em um processo gradual, para o agravamento do estresse, levando ao estágio crônico, Síndrome de Burnout. (24)

Portanto, pode-se inferir que o enfermeiro (a) necessita desenvolver competências para apoiar, não só o paciente em estágio final, como também os seus familiares. Para isso, é necessário desenvolver adequado preparo e apoio psíquico frente às questões que envolvem as perdas, caso contrário, este profissional estará cultivando mais sofrimento e estresse laboral, podendo atingir a severidade dos estágios patológicos crônicos. Torna-se relevante a valorização dessas questões através de projetos internos capazes de oferecer suporte físico e psíquico de forma humanizada aos(as) en- fermeiros(as), proporcionando assim, cuidados os profissional que cuida.

\section{CONSEQUÊNCIAS PATOLÓGICAS DOS SENTIMENTOS GERADOS NO ENFERMEIRO (A) DURANTE O ENFRENTAMENTO DA MORTE}

Refletir a respeito dos motivos da angústia do ser humano ao enfrentar a própria finitude é o primeiro passo para garantir o entendimento dos reflexos patológicos desenvolvidos pela enfermagem frente o enfrentamento da morte. ${ }^{(6)}$

A encruzilhada em que se encontraram e ainda se encontram as mais variadas culturas, principalmente na região ocidental, que tem experimentado mudanças importantes em sua visão de morte, influenciam fortemente o estado emocional e psíquico dos enfermeiros (as) dos tempos modernos gerando consequências patológicas graves.

Para refletir sobre tais consequências, torna-se necessário conhecer uma das situações de staff psicológico intensamente apontado nos estudos analisados: o estresse. O termo "estresse" tem sido muito utilizado e estudado sob vários aspectos e visões. Partindo da premissa de que não há um consenso exato sobre o significado da palavra estresse, estudos o representam como uma inadequada tentativa de adaptação à mudança imposta por mecanismos externos, ou seja, o estresse é ocasionado pela inútil forma de enfrentar as adversidades. Assim, ele revela-se como cansaço emocional e uma reação psicológica, cujos fatores etiológicos podem ser oriundos de eventos externos ou internos. ${ }^{(29-30)}$

Vale lembrar que há uma imensa quantidade de fatores que potencializam o estresse, o seu desenvolvimento e o seu agravamento. A começar pelos aspectos individuais, que consiste na maneira como cada indivíduo reage às tensões diárias, sem deixar de acrescentar os aspectos culturais e sociais aos quais estão submetidos. Situações como problemas familiares, acidentes, doenças, mortes, conflitos pessoais, dificuldade financeira, desem- 
prego, aposentadoria, problemas no ambiente de trabalho entre outros podem ser vivenciados de forma diferente por indivíduos distintos, em um mesmo contexto histórico e sociocultural. ${ }^{(29)}$

Isso significa dizer, que embora o contexto de experiência com as questões da terminalidade possam se repetir de forma rotineira, este será vivenciado de forma única pelo profissional, que poderá desenvolver mecanismos estressores fundamentados de acordo aos recursos culturais e psico-espirituais de cada indivíduo.

Os efeitos psíquicos caracterizam-se em reações ao estresse a ansiedade, insônia, pânico, angústia, depressão, relações interpessoais mal estabelecidas e hipersensibilidade emotiva. A extensão e cronicidade desses efeitos podem vir a ocasionar síndromes, como a de Burnout que é considerada como uma reação à pressão emocional crônica por lidar excessivamente com pessoas. ${ }^{(30-31)}$

As fases que caracterizam o Burnout como sendo: exaustão emocional, despersonalização e redução da realização profissional no trabalho. Outro fator é a exaustão emocional é sinalizada como sentimento de frustração, falta de entusiasmo e energia por parte dos trabalhadores por perceberem a sua indisposição em desenvolver o seu trabalho. Os aspectos mais relevantes da segunda fase do Burnout: a despersonalização, esta é vista como o desenvolvimento de uma insensibilidade emocional que antecede a (des) humanização nas relações interpessoais. E por último, considerada a mais desgastante fase da patologia, a diminuição da realização pessoal no trabalho - que é constituída por uma tendência do trabalhador a tornar-se insatisfeito e se auto negativar profissionalmente, e, em consequência disso, ocorre o declínio no seu sentimento de competência. (31)

Então foi possível constatar que o estresse fragmenta o equilíbrio psíquico e fisiológico do indivíduo, fazendo com que o mesmo utilize todas as reservas de energia, inibindo assim os mecanismos de enfrentamento do contexto ao qual foi exposto. A depender do período e do nível de estresse, o indivíduo pode vir a sofrer consequências graves podendo evoluir para patologias crônicas como a síndrome de Burnout.

\section{METODOLOGIA}

Trata-se de uma revisão integrativa de caráter exploratório, que reúne e sintetiza resultados de diferentes pesquisas sobre um determinado tema, contribuindo de forma significativa para o aprofundamento do conhecimento do tema investigada. Esse tipo de pesquisa apesar de ser considerada ampla, permite incluir literatura teórica e empírica bem como estudos com diferentes abordagens metodológicas (quantitativa e qualitativa). ${ }^{(32-33)}$

Realizou-se a busca dos artigos sobre o tema por meio dos seguintes descritores rastreados no Descritores em Ciências da Saúde (DeCS): morte; emoções; enfermeiros (as). Como critérios de inclusão, estabeleceram-se artigos na íntegra e em português, publicados em periódicos de Enfermagem no período de 2001 a 2011 e indexados nas seguintes base de dados Scientific Electronic Library Online (Scielo) e Literatura Latino-Americana em Ciências de Saúde (Lilacs), atendendo aos descritores deste estudo. $\mathrm{O}$ acesso às fontes de pesquisa ocorreu no ano de 2011.

A fim de garantir que os artigos selecionados pertencessem a mesma linha temática, após o levantamento das publicações, os resumos foram lidos e analisados, de acordo com os critérios de inclusão. Em seguida, procedeu-se a coleta dos dados através de um quadro, destacando-se a base de dados, campo, sujeitos do estudo, periódico, ano e região de publicação, como pode ser conferido no Apêndice A. Foram excluídos desta pesquisa os artigos que não se adequavam ao objeto de estudo que circunscreveu sobre os sentimentos gerados no processo morte/morrer em enfermeiros (as). Por fim, realizou-se a análise e discussão dos dados produzidos de forma dissertativo-discursivo.

A análise dos artigos selecionados, em relação ao objetivo traçado, pautou-se na abordagem metodológica referente à revisão integrativa. Sendo 
assim, tanto a análise quanto a síntese dos dados foram realizadas de forma descritiva, o que possibilitou observar, calcular, descrever e classificar os dados, visando reunir o conhecimento produzido sobre o tema explorado na presente revisão.

\section{RESULTADOS E DISCUSSÕES}

Com base nos critérios de inclusão, foram rastreados 31 artigos, destes apenas 9 (nove) estiveram de acordo com o objeto de estudo. O Sciello indexou o maior quantitativo de trabalhos entre as bases de dados, totalizando em $67 \%$ dos artigos seguido pela base Lilacs com $33 \%$ dos trabalhos. Essa estatística se deve ao fato do Sciello contemplar estudos produzidos com enfoque no contexto da área de saúde. Além disso, proporciona uma forma eficiente de assegurar a visibilidade e acesso universal as suas literaturas científicas.

O período de estudo transcorreu entre os anos de 2001 a 2011, porém as 9 (nove) pesquisas selecionadas estiveram entre 2005 a 2010 relacionados ao objeto de estudo que circunscreveu sobre os sentimentos gerados no processo morte/morrer em enfermeiros. A Revista Brasileira de Enfermagem está entre os periódicos que mais publicaram sobre a temática, com $23 \%$ das publicações, sobretudo por ser o periódico mais antigo da enfermagem brasileira, as demais revistas que obtiveram $11 \%$ das publicações foram a Revista Enfermagem UERJ, Revista Gaucha de Enfermagem, Acta Paulista, Revista Latino Americana de Enfermagem, Texto Contexto, Revista Escola de Enfermagem da USP, O Mundo da Saúde. A pesquisa de campo foi o percurso metodológico mais utilizado, contabilizando $69 \%$ artigos. Esse tipo de pesquisa tem sido constantemente utilizado pelo fato de proporcionar maior enriquecimento e aprofundamento das perspectivas do pesquisador.

Dentre os estudos de campo incluídos neste trabalho, destacam-se como sujeitos mais abordados os enfermeiros com $60 \%$, seguidos pelos discentes de enfermagem com $30 \%$ e os docentes de en- fermagem com $10 \%$. Isso se deve ao fato de serem os sujeitos de enfoque temático deste estudo.

Vale ressaltar que a região Sudeste teve maior predominância de publicações com $45 \%$ quando comparado com as regiões Centro-oeste com 33\% e Sul com $22 \%$. Constatou-se que não foram encontrados trabalhos publicados nas regiões Norte e Nordeste que abrangessem a temática desta pesquisa. Esse resultado reflete que a literatura científica destas regiões enfrenta graves barreiras de distribuição e disseminação, o que limita o acesso e o uso da informação científica gerada localmente.

No que se refere às impressões sobre a temáti$\mathrm{ca}$, o primeiro grupo de artigos analisados tratam a respeito da negação da morte e os sentimentos ao fim da vida, as produções científicas de enfermagem discutem acerca da finitude humana ao longo de décadas, a enfermeira da época passada seguia um comportamento padrão, contendo aspectos dentre os quais, se enquadravam: habilidade de confortar o paciente e seus familiares e para realização de analgesia; prestar cuidado adequado no preparo do corpo e não se envolver sentimentalmente. Os autores consideram que embora haja estudos e pesquisas sobre a morte, estes ainda são carregados de valores socioculturais, o que os mesmos classificam como "verdades comuns".(3)

Os artigos trazem críticas pertinentes no que se refere à literatura encontrada sobre a temática, estabelecendo a dificuldade enfrentada ao falar, escutar e escrever sobre um "tabu" social. Junto a isso, destacou-se que enfermeiros (as) embora considerem a morte como algo natural relatam ao mesmo tempo, sentimentos de medo, sentem-se impotentes, tristes, culpados (as), fracassados (as). Reflexo a esses sentimentos o despreparo sobre a formação profissional caracteriza-se deficitária quanto a abordagem na academia sobre os temas referentes ao fim da vida o que pode ser justificado, entre outras causas, pelo medo e distanciamento revelado pelos próprios docentes que também se encontram enclausurados no tabu social no que se refere à temática. Esses discursos só fazem confirmar a visão dos autores de que os estudos da morte es- 
tão impregnados pelas sabedorias culturais e relacionados a desestabilização emocional do enfermeiro (a) com questões existenciais.

Alguns artigos que enfocam sobre o desconforto durante o preparo do corpo afirmam que o profissional enfermeiro (a) envolvido neste processo de preparo do corpo, considera sua disponibilidade interna, seus valores e conceitos relacionados a limitação da vida e suas experiências pessoais vem à tona, tendo que refletir sobre sua própria morte, suas perdas e luto. Segundo os autores desse estudo, a finitude é um tema angustiante, pois desafia o profissional que está inserido num contexto sócio-histórico de negação da morte.

Nesse estudo, muitos autores relatam que o medo da morte está intimamente ligado à separação, deformação do corpo, mudanças de cheiro e aparência. Isso pode ser verificado através da literatura incluída neste estudo, no qual os autores revelam as dificuldades dos professores de graduação em trabalhar com os acadêmicos assuntos sobre a morte, revelando sentimentos de angústia, sofrimento, dor física, além do alto nível de estresse e medo. O preparo do corpo é revelado como um momento angustiante. ${ }^{(25)}$

Outra questão levantada pelos autores foi a relação dos avanços tecnológicos com a obstinação terapêutica, assim o desconforto é gerado no enfermeiro ao ter de efetuar procedimentos que prolongam a vida, mesmo não estando de acordo, causando-lhe sofrimento. Os profissionais de saúde sofrem os impactos da perda, e tem dificuldade para elaborar o próprio luto. Outros autores abordaram que na sociedade ocidental a morte é considerada pelos profissionais de saúde como um fracasso. Para a enfermagem a morte é vista como a maior vilã de seu trabalho, uma vez que, de maneira geral, são educados para cuidar somente da vida. ${ }^{(34)}$

Contudo pode-se perceber, quando o morrer se revela prolongado e doloroso, a morte pode ser vista como alívio. Diante das discussões explanadas pelos autores, pode-se perceber que embora as maneiras de posicionamentos com relação à morte e as doenças tenham mudado a partir dos avanços da ciência e da tecnologia, a elaboração das perdas e a aceitação do luto ainda tem muitos espaços para conquistar. Estudos realizados com enfermeiros (as) que trabalham em Unidades de Terapia Intensiva revelam que tais unidades, pensadas a princípio, para salvar vidas, têm sido utilizadas, em muitos casos, para a sofrida obstinação terapêutica provocando na equipe de enfermagem tanto prazer e satisfação como também sofrimento e desgaste. ${ }^{(22)}$

O prazer sempre relacionado ao tratamento bem sucedido; e o desgaste quando o processo de morte é prolongado e doloroso. As literaturas no que se refere a visão da unidade de terapia intensiva também a mostra como um local para a vida e a insatisfação gerada pelos enfermeiros (as) pelo fato da unidade ser vista como local de morte e sofrimento. Assim, os pacientes que ficam muito tempo internados gera insatisfação, pois os profissionais reconhecem que os investimentos não estão gerando progresso, reconhecendo a morte como um fracasso. A obstinação terapêutica gera ansiedade e insatisfação dos profissionais, com isso a morte do paciente pode trazer um alívio e ao mesmo tempo gerar culpa. Sentimentos de desânimo, insatisfação e frustração também permeiam os profissionais de enfermagem devido a pouca valorização dada aos mesmos, principalmente em assuntos sobre o prolongamento da vida. ${ }^{(21)}$

No que diz respeito a dor incontrolável dos pacientes, os artigos mostram que o profissional de enfermagem está diante de vários sentimentos frente ao paciente e familiares, e muitas vezes entram em conflito em como se posicionar, já que nem sempre podem aliviar a dor e elaborar as perdas. Os sentimentos gerados durante a assistência é a impotência e inconformação do profissional devido ao despreparo emocional e psicológico. Os estudos mostram também que a dor incontrolável do paciente gera desgaste emocional no profissional e o sentimento de impotência vem à tona. Outros textos mostram que o trabalho do enfermeiro deve ter em sua essência a assistência ao paciente 
holisticamente, isso significa que o cuidado deve atender as múltiplas dimensões, inclusive durante o processo terminal e que sente dor.

Outros estudos salientam sobre o despreparo do enfermeiro no enfrentamento da morte, nesse sentido, ao longo dos tempos a morte deixou de ocorrer em casa e passou a ser nos hospitais. Assim a família que sofre com a condição de saúde de seu familiar, ainda tem de enfrentar as dificuldades, protocolos e horários que são impostos pelas instituições hospitalares no que se refere ao acompanhamento e visitas. A família muitas vezes é interpretada como um incômodo para os profissionais, devido à cobrança social que recai sobre a equipe de saúde como uma obrigação de curar o doente. Logo, a ocorrência de uma morte gera sentimentos de impotência, frustração e culpa e tais sentimentos são coadjuvantes para a fuga do contato com familiares. ${ }^{(1)}$

Os autores também investigaram sobre o preparo de acadêmicos de enfermagem frente à morte. Esses trabalhos mostram que os estudantes não souberam se posicionar frente às questões referentes ao fim da vida e os sentimentos diante desta realidade foram, entre outros, frustração e impotência. Além disso, demonstraram medo e distanciamento do contato com familiares como forma de defesa e sinalizaram ainda sobre a falta de apoio dos preceptores de estágio, refletindo em despreparo desses docentes. ${ }^{(26)}$

O despreparo de estudantes e a deficitária abordagem na academia sobre os temas referentes ao fim da vida podem ser justificados, entre outras causas, pelo medo e distanciamento revelado pelos próprios docentes que também se encontram enclausurados no tabu social no que se refere à temática. Assim o contato com familiares soma mais um fator estressante e embaraçoso, tendo em vista que o enfermeiro (a), de maneira geral, não sabem como se posicionar frente a essa situação.

Um grupo de trabalho traz uma discussão sobre o sofrimento psíquico dos enfermeiros que sentem dificuldade de enfrentar a finitude e torna-se ainda mais difícil quando se refere à morte da criança e do adolescente, pois esta é entendida como interrupção de um ciclo biológico e tem provocado sentimentos de frustração, pesar, silêncio, dor, culpa e angústia.

Este trabalho deixa claro o sofrimento diário vivenciado por enfermeiros (as) e a necessidade de urgente intervenção neste quadro, de forma a ajudá-los a compreender o morrer como um processo que precisa ser vivenciado, e que o luto é uma reação natural e necessária no processo de enfrentamento das perdas dos pacientes que estavam sob seus cuidados, independente da idade ou fase da vida.

Para isso, tem sido proposto pelos autores que haja uma reforma institucional capaz de preparar os acadêmicos para prestação de cuidados até o fim da vida. Além disso, que as instituições de saúde, através da educação permanente busquem medidas de refletir junto aos profissionais sobre as perdas e o luto como forma de prevenir o desenvolvimento da síndrome de Burnout. Os autores também trazem uma discussão sobre a falta de tempo para elaborar perdas de pacientes, posicionamento diante da dor, que em alguns casos não se consegue aliviar. ${ }^{(5)}$

Diante disso, pode ocorrer uma sobrecarga emocional, se for levado em consideração o fato de não obterem formas de compartilhamento do próprio sofrimento que ocasionam em alguns casos uma síndrome laboral- a síndrome de Burnout. Outros autores, em estudos análogos destacam a fragilidade, incerteza e medo gerados pelo processo de trabalho do enfermeiro (a) no setor de emergência, local onde a morte se impõe com alta frequência desperta sentimentos como: tristeza, raiva, fuga, perda, negação, frustração, na maioria dos casos, não compartilhados, prejudicam o bem-estar do profissional e a interação entre o cuidador e o ser que demanda cuidado. (35)

As reações emocionais mais frequentes dos enfermeiros (as) frente às questões existenciais são conhecidas e amplamente analisadas, sendo que os estudos abordam desde problemas de formação acadêmica até dificuldades a nível pessoal e 
institucional decorrentes do contato com a terminalidade humana.

\section{CONSIDERAÇÕES FINAIS}

A realização deste estudo evidenciou que a maioria dos artigos analisados tratam sobre a influência cultural do significado da morte e reflete no enfrentamento da mesma nos dias atuais, revelando-se de maneira silenciada com sentimentos de medo e angústia. Os achados deste trabalho corroboram o pressuposto que uma sociedade capitalista com enfoque no progresso e avanços tecnológicos está fazendo com que profissionais enfermeiro (a)s percebam a cura como única opção terapêutica.

Dessa forma, podem acabar sofrendo com o prolongamento da vida do outro, que pode vir acompanhada da dor incontrolável e sofrimento da família. Todas estas questões são destacadas pelos autores como fatores desencadeantes de sentimentos de fracasso, medo, impotência, culpa, isolamento, silenciamento e negação. Tais emoções se revelam como consequência do despreparo do enfermeiro sobre as questões das perdas e deficitária abordagem sobre o tema durante a graduação e as próprias crenças culturais e religiosas que cada ser humano traz consigo. Em muitos casos essa dificuldade de enfretamento gera estresse e sofrimento psíquico que ao longo do tempo pode vir a desenvolver uma condição de estresse crônica como a síndrome de Burnout.

Esta abordagem do material recuperado constitui-se apenas em um recorte da literatura cientifica sobre o enfrentamento do processo morte e morrer em que a enfermagem tem demonstrado interesse sobre o assunto, porém existem poucos estudos sobre o tema. Foi observado também que os artigos recentes retratam conteúdos já trabaIhados em pesquisas anteriores, sem trazer novas abordagens sobre atitudes e maneiras de enfrentar a morte. Demonstrando que as mesmas dificuldades do passado perpetuam até os dias atuais, sem avanços com relação às questões da finitude. $O$ despreparo do enfermeiro (a) reflete em um cui- dado deficitário que gera situações (des)humanas e prejudiciais ao cuidado humano no fim da vida. O profissional, além de estar inserido num contexto sócio-histórico de negação da morte, com uma formação profissional caracterizada pela ênfase nos aspectos teórico-técnicos, é estimulado a não demonstrar seus sentimentos, sendo impedido de elaborar as perdas e o próprio luto.

O descuido diante da problemática que se revela a negação da morte tem crescido e alcançado dimensões que ultrapassam os limites da mente humana e tem revelado como consequência o desgaste emocional. A questão se agrava ainda mais quando se reflete sobre a desproporção entre o contato do enfermeiro com o fim da vida e a frequência que se fala sobre a morte e os sentimentos destes em relação a ela. Como revela em um dos estudos a enfermagem é uma das profissões mais desgastante dos últimos tempos.

O estresse diante de uma terapêutica que se revelou incapaz de salvar a vida do paciente, deixando claro que a tecnologia embora avance a cada momento não se revela onipotente, o enfermeiro demonstra sentimentos de pesar, angústia e se defronta com o sofrimento psíquico e a despersonalização crônica. A enfermagem ainda está presa à cultura da cura e não da prevenção, ao alívio do sofrimento e a recuperação da saúde. Por todos esses aspectos ela está voltada para as necessidades do cliente e é considerada como uma profissão de ajuda. Portanto, torna-se necessário discutir mais e melhor em torno dos sentimentos e ações geradas frente à morte, bem como, as formas de prevenção das questões no âmbito psíquico para atingir ajustamentos perante a terminalidade humana.

Este estudo indica que os profissionais de Enfermagem se encontram numa situação de fragilidade para atuar junto ao paciente fora de possibilidades terapêuticas. Percebe-se que existe uma lacuna evidente entre a formação do profissional e a manutenção do seu treinamento e suporte na instituição de saúde. Despertando a necessidade de mais investimentos das instituições no amparo aos enfermeiros com relação à elaboração do luto, 
proporcionando-Ihe espaços que, se bem conduzidos, favorecem o fortalecimento dos sujeitos e maior preparo frente às questões existências oferecendo-lhes desta forma, um suporte psicológico capaz de proporcionar cuidados ao profissional que cuida.

Ressalta-se que este trabalho merece ter continuidade tendo em vista que o enfermeiro e a categoria profissional tem na essência de sua profissão a capacidade de desenvolver os cincos sentidos para garantir cuidado holístico aos pacientes, deve-se permitir saborear, escutar, enxergar, falar, tocar e sentir a morte como parte do cuidado demandado pela pessoa que é cuidada e garantir o bem estar no trabalho.

\section{REFERÊNCIAS}

1. Bernieri J, Hirdes A. O preparo dos acadêmicos de enfermagem brasileiros para vivenciarem o processo morte-morrer. Texto \& contexto enferm. [periódico na internet]. 2007 [acesso em 27 set. 2011]; 16(1). Disponível em: http:// www.scielo.br/pdf/tce/v16nl/allv16nl.pdf.

2. Loureiro AML. A batuta da morte a orquestrar a vida. Interface comun. saúde educ. [periódico na internet]. 2008 [acesso em O2 set. 2011];12(27). Disponivel em: http://www.scielo.br/pdf/icse/ v12n27/a14v1227.pdf

3. Silva KS, Ribeiro RG, Kruse MHL. Discursos de enfermeiras sobre morte e morrer: vontade ou verdade?. Rev. bras. enferm. [periódico na internet] 2009 [acesso em 05 ago. 2011]; 62(3). Disponível em: http://www.scielo.br/pdf/reben/ v62n3/19.pdf

4. Souza ML de et al. O Cuidado em Enfermagem - uma aproximação teórica. Texto \& contexto enferm. [periódico na internet]. 2005 [acesso em 19 jul. 2011];14(2). Disponível em: http://www. scielo.br/pdf/tce/v14n2/al5v14n2.pdf

5. Salomé GM, Cavali A, Espósito VHC. Sala de emergência: o cotidiano das vivências com a morte e o morrer pelos profissionais de saúde. Rev. bras. enferm. [periódico na internet]. 2009 [acesso em 29 ago. 2011]; 62(5). Disponível em: http://www.scielo.br/pdf/reben/v62n5/O5.pdf
6. Bellato R, Carvalho EC. O jogo existencial e a ritualização da morte. Rev. latinoam. enferm. [periódico na internet]. 2005 [acesso em 27 set. 2011];13(1). Disponível em: http://www. scielo.br/pdf/rlae/v13nl/v13nlal6.pdf

7. Ferreira, LRC, Martino MMF de. O estresse do enfermeiro: análise das publicações sobre o tema. Rev. ciênc. méd. [periódico na internet]. 2006 [acesso em 21 out. 2011];15(3). Disponível em: http://www.puccampinas.edu.br/centros/ ccv/revcienciasmedicas/artigos/931.pdf

8. Moreira $D$ de $S$ et al. Prevalência da síndrome de burnout em trabalhadores de enfermagem de um hospital de grande porte da Região Sul do Brasil. Cad. saúde pública. [periódico na internet]. 2009 [acesso em Ol nov. 2011];25(7). Disponivel em: http://www.scielosp.org/pdf/csp/ v25n7/14.pdf

9. Ross E K. Morte: estágio final de evolução. Rio de Janeiro: Editora Record; 1996. p. 220.

10. Caputo RF. O homem e suas representações sobre a morte e o morrer: um percurso histórico. Rev. multidiscip. UNIESP Saber acadêmico. 2008;6.

11. Reis JJ. A morte é uma festa: ritos fúnebres e revolta popular no Brasil do século XIX. São Paulo: Companhia das Letras; 1991.

12. Ariès P. História da morte no ocidente. Rio de Janeiro: Ediouro; 2003.

13. Silva DJ da. Em nome do padre, do filho e do espírito santo: ritos de morte em Goiás no século XIX. Anais do $26^{\circ}$ Simpósio Nacional de História. 17-22 jul. 2011; São Paulo [internet]: Anpuh; 2O11. Disponível em: http://www.snh2Ol1. anpuh.org/resources/anais/14/1300892990_ ARQUIVO_Emnomedopadre,dofilhoedoespirit osanto-ritosdemorteemGoiasnoseculoXIX.pdf Acesso em: 10 abr. 2012

14. Pinho LMO, Barbosa MA. A morte e o morrer no cotidiano de docentes de enfermagem. Rev. enferm. UERJ. [periódico na internet]. 2008 [acesso em O5 ago. 2011]; 16(2). Disponível em: http://www.facenf.uerj.br/v16n2/v16n2al7.pdf

15. Carvalho LSO, Barbosa MA. A morte e morrer no cotidiano de estudantes de enfermagem. Rev. enferm. UERJ. [periódico na internet]. 2006 [acesso em Ol jul. 2O11]; 14(4). Disponível 
em: http://www.facenf.uerj.br/v14n4/v14n4a1O. pdf

16. Baggio MA, Callegaro GD, Erdmann AL. Compreendendo as dimensões de cuidado em uma unidade de emergência hospitalar. Rev. bras. enferm. [periódico na internet]. 2009 [acesso em 17 jul. 2011]; 62(3). Disponível em: http://www.scielo.br/pdf/reben/v6ln5/aO4v6ln5. pdf

17. Silva AM da. Competências para o gerenciamento em enfermagem: revisão de literatura. Rev. gaúch. enferm. [periódico na internet]. 2009 [acesso em $\mathrm{Ol}$ nov. 2011]; 8(47). Disponível em: http://www.lume.ufrgs.br/ bitstream/handle/10183/24328/000746776. pdf

18. Martino MMF de, Misko MD. Estados emocionais de enfermeiros no desempenho profissional em unidades críticas. Rev. Esc. Enferm. USP. [periódico na internet]. 2004 [acesso em 19 set. 2011]; 38(2). Disponível em: http://www.scielo.br/pdf/reeusp/v38n2/O6.pdf

19. Celich KLS. Dimensões do processo de cuidar na enfermagem: um olhar da enfermeira. Texto \& contexto enferm. [periódico na internet]. 2005 [acesso em 30 out. 2011]; 14(3). Disponível em: http://www.lume.ufrgs.br/ bitstream/handle/10183/4931/000417203.pdf

2O. Silva MIGA. Os alunos de enfermagem do $4^{\circ}$ ano da Faculdade de Ciências da Saúde - Universidade Fernando Pessoa perante as práticas de Distanásia num doente em fase terminal [monografia]. Porto Alegre: Universidade Fernando Pessoa; 2008 [acesso em $\mathrm{O} 3$ nov. 2Ol1]. Disponível em: https://bdigital. ufp.pt/dspace/bitstream/10284/990/3/13890. $\mathrm{pdf}$

21. Gutierrez BAO, Ciampone MHT. O processo de morrer e a morte no enfoque dos profissionais de enfermagem de UTIs. Rev. Esc. Enferm. USP. [periódico na internet]. 2007 [acesso em 25 jan. 2012]; 4l(4). Disponível em: http://www. scielo.br/pdf/reeusp/v4ln4/16.pdf

22. Sanches PG, Carvalho MDdeB. Vivência dos enfermeiros de unidade de terapia intensiva frente à morte e o morrer. Rev. gaúch. enferm. [periódico na internet]. 2009 [acesso em 29 ago. 2011]; 3O(2). Disponível em: http://seer.
ufrgs.br/RevistaGauchadeEnfermagem/article/ view/3294/6687

23. Novaes MRCG, Trindade EM. A morte e o morrer: considerações bioéticas sobre a eutanásia e a finitude da vida no contexto da relação médico-paciente. Com. Ciências Saúde. [periódico na internet]. 2007 [acesso em 3 nov. 2OII]; 18(3). Disponível em: http://www.fepecs. edu.br/revista/Vol18_lartO8.pdf

24. Jodas DA, Haddad M do C. Síndrome de Burnout em trabalhadores de enfermagem de um pronto socorro de hospital universitário. Acta paul. enferm. [periódico na internet]. 2009. [acesso em 23 out. 2011]; 22(2). Disponível em: http://www.scielo.br/pdf/ape/ v22n2/a12v22n2.pdf

25. Pinho LMO, Barbosa MA. A relação docente acadêmico no enfrentamento do morrer. Rev. Esc. Enferm. USP. [periódico na internet]. 2011 [acesso em O4 ago. 2011];44(1). Disponível em: http://www.scielo.br/pdf/reeusp/v44nl/ al5v44nl.pdf

26. Brêtas JR da S, Oliveira JR de, Yamaguti L. Reflexões de estudantes de enfermagem sobre morte e o morrer. Rev. Esc. Enfermagem USP. [periódico na internet]. 2006 [acesso em 14 ago. 2011]; 4O(4). Disponível em: http://www. scielo.br/pdf/reeusp/v4On4/v4On4aO4.pdf

27. Rego S, Palácios M. A finitude humana e saúde pública. Cad. saúde pública. [periódico na internet]. 2006 [acesso em $\mathrm{O} 2$ nov. 2011];22(8). Disponivel em: http://www.scielo.br/pdf/csp/ v22n8/25.pdf

28. Stacciarini JM, Tróccoli BT. O estresse na atividade ocupacional do enfermeiro. Rev. latinoam. enferm. [periódico na internet]. 2001 [acesso em 11 set. 2O11];9(2). Disponível em: http://www.scielo.br/pdf/rlae/v9n2/11510.pdf

29. Abreu KL de et al. Estresse ocupacional e Síndrome de Burnout no exercício profissional da psicologia. Psicol. cienc. prof. [periódico na internet]. 2000 [acesso em 31 out. 2011];22(2). Disponível em: http://pepsic.bvsalud. org/scielo.php?script=sci_arttext\&pid=S14149893 2002000200004\&lng=pt\&nrm=iso.pdf

30. Fávero MAB, Santos MA dos. Autismo infantil e estresse familiar: uma revisão sistemática da literatura. Psicol reflex. crit. [periódico na 
internet]. 2005 [acesso em 30 out. 2011];18(3). Disponível em: http://www.scielo.br/pdf/prc/ v18n3/a1Ov18n3.pdf

31. Carlotto MS, Palazzo LS. Síndrome de burnout e fatores associados: um estudo epidemiológico em professores. Cad. saúde pública. [periódico na internet]. 2006 [acesso em 28 out. 2011]; 22(5). Disponível em: http://www.scielo.br/pdf/ csp/v22n5/14.pdf

32. Mendes KDS, Silveira RCCP, Galvão CM. Revisão integrativa: método de pesquisa para a incorporação de evidências na saúde e na enfermagem. Texto \& contexto enferm. [periódico na internet]. 2008 [acesso em 17 abr. 2012]; 17(4). Disponível em: http://www.scielo.br/ pdf/tce/v17n4/18.pdf

33. Pompeo DA, Rossi LA, Galvao CM. Revisão integrativa: etapa inicial do processo de validação de diagnóstico de enfermagem. Acta paul. enferm. [periódico na internet]. 2009 [acesso em 17 abr. 2012];22(4). Disponível em: http://www.scielo.br/pdf/ape/v22n4/a14v22n4. pdf

34. Costa JC, Lima RAG. Luto da equipe: revelações dos profissionais de enfermagem sobre o cuidado à criança/adolescente no processo de morte e morrer. Rev. latinoam. enferm. [periódico na internet]. 2005 [acesso em 17 fev. 2012];13(2). Disponível em: http://www.scielo.br/scielo.php?pid=SO1O4$11692005000200004 \&$ script=sci_arttext

35. Kovács MJ. Sofrimento da equipe de saúde no contexto hospitalar: cuidando do cuidador profissional. Mundo saúde. [periódico na internet]. 2010 [acesso em 10 jul. 2011]; 34(4). Disponível em: http://www.saocamilo-sp.br/pdf/ mundo_saude/79/420.pdf 


\section{APÊNDICE A - Quadro analítico sobre a coleta de dados}

Quadro 1 - Coleta de dados dos artigos científicos.

\begin{tabular}{|c|c|c|c|c|c|c|}
\hline Título & $\begin{array}{l}\text { BASE DE } \\
\text { DADOS }\end{array}$ & CAMPO & $\begin{array}{c}\text { SUJEITOS DO } \\
\text { ESTUDO }\end{array}$ & PERIÓdICO & ANO & $\begin{array}{c}\text { REGIÃO DE } \\
\text { PUBLICAÇÃO }\end{array}$ \\
\hline $\begin{array}{c}\text { A morte e o morrer no } \\
\text { cotidiano de docentes } \\
\text { de enfermagem }\end{array}$ & Lilacs & $\begin{array}{l}\text { Pesquisa } \\
\text { de campo }\end{array}$ & $\begin{array}{l}\text { Docentes de } \\
\text { enfermagem }\end{array}$ & $\begin{array}{l}\text { Revista de } \\
\text { Enfermagem } \\
\text { UERJ }\end{array}$ & 2008 & $\begin{array}{l}\text { Centro- } \\
\text { Oeste }\end{array}$ \\
\hline $\begin{array}{c}\text { iscursos de } \\
\text { enfermeiras sobre } \\
\text { morte e morrer: } \\
\text { vontade ou verdade? }\end{array}$ & Scielo & $\begin{array}{l}\text { Revisão } \\
\text { de } \\
\text { literatura }\end{array}$ & $\begin{array}{c}\text { Profissionais } \\
\text { de } \\
\text { enfermagem }\end{array}$ & $\begin{array}{l}\text { Revista } \\
\text { Brasileira de } \\
\text { Enfermagem }\end{array}$ & 2009 & $\begin{array}{l}\text { Centro- } \\
\text { Oeste }\end{array}$ \\
\hline $\begin{array}{l}\text { LUTO DA EQUIPE: } \\
\text { Revelações dos } \\
\text { profissionais de } \\
\text { enfermagem sobre } \\
\text { o cuidado à criança/ } \\
\text { adolescente no } \\
\text { processo de morte e } \\
\text { morrer }\end{array}$ & Scielo & $\begin{array}{l}\text { Pesquisa } \\
\text { de campo }\end{array}$ & $\begin{array}{c}\text { Profissionais } \\
\text { de } \\
\text { enfermagem }\end{array}$ & $\begin{array}{l}\text { Revista. } \\
\text { Latino- } \\
\text { Americana }\end{array}$ & 2005 & Sudeste \\
\hline
\end{tabular}

Fonte: Elaborado pelas próprias autoras 2012.

\section{APÊNDICE A - Quadro analítico sobre a coleta de dados}

Quadro 2 - Coleta de dados dos artigos científicos.

\begin{tabular}{|c|c|c|c|c|c|c|}
\hline Título & $\begin{array}{l}\text { BASE DE } \\
\text { DADOS }\end{array}$ & CAMPO & $\begin{array}{l}\text { SUJEITOS DO } \\
\text { ESTUDO }\end{array}$ & PERIÓdICO & ANO & $\begin{array}{l}\text { REGIÃO DE } \\
\text { PUBLICAÇÃO }\end{array}$ \\
\hline $\begin{array}{c}\text { O preparo dos } \\
\text { acadêmicos de } \\
\text { enfermagem brasileiros } \\
\text { para vivenciarem o } \\
\text { processo morte -morrer }\end{array}$ & Scielo & $\begin{array}{l}\text { Pesquisa } \\
\text { de campo }\end{array}$ & $\begin{array}{l}\text { Estudantes de } \\
\text { enfermagem }\end{array}$ & $\begin{array}{c}\text { Texto } \\
\text { Contexto } \\
\text { Enfermagem }\end{array}$ & 2007 & Sul \\
\hline $\begin{array}{c}\text { Profissionais de } \\
\text { enfermagem frente ao } \\
\text { processo de morte em } \\
\text { unidades de terapia } \\
\text { intensiva }\end{array}$ & Scielo & $\begin{array}{l}\text { Pesquisa } \\
\text { de campo }\end{array}$ & $\begin{array}{l}\text { Profissionais } \\
\text { de } \\
\text { enfermagem }\end{array}$ & $\begin{array}{l}\text { Acta Paulista } \\
\text { enfermagem }\end{array}$ & 2006 & Sudeste \\
\hline $\begin{array}{l}\text { Reflexões de estudantes } \\
\text { de enfermagem } \\
\text { sobre morte e o morrer }\end{array}$ & Scielo & $\begin{array}{l}\text { Pesquisa } \\
\text { de campo }\end{array}$ & $\begin{array}{l}\text { Estudantes de } \\
\text { enfermagem }\end{array}$ & $\begin{array}{c}\text { Revista } \\
\text { Escola } \\
\text { Enfermagem } \\
\text { USP }\end{array}$ & 2006 & Sudeste \\
\hline
\end{tabular}

Fonte: Elaborado pelas próprias autoras 2012. 


\section{APÊNDICE A - Quadro analítico sobre a coleta de dados}

Quadro 3 - Coleta de dados dos artigos científicos

\begin{tabular}{|c|c|c|c|c|c|c|}
\hline Título & $\begin{array}{l}\text { BASE DE } \\
\text { DADOS }\end{array}$ & CAMPO & $\begin{array}{c}\text { SUJEITOS DO } \\
\text { ESTUDO }\end{array}$ & PERIÓDICO & ANO & $\begin{array}{c}\text { REGIÃO DE } \\
\text { PUBLICAÇÃO }\end{array}$ \\
\hline $\begin{array}{c}\text { Sala de Emergência: o } \\
\text { cotidiano das vivências } \\
\text { com a morte e o morrer } \\
\text { pelos profissionais de } \\
\text { saúde }\end{array}$ & Scielo & $\begin{array}{c}\text { Pesquisa } \\
\text { de } \\
\text { campo }\end{array}$ & $\begin{array}{c}\text { Profissionais } \\
\text { de } \\
\text { enfermagem }\end{array}$ & $\begin{array}{l}\text { Revista } \\
\text { brasileira de } \\
\text { enfermagem }\end{array}$ & 2009 & Centro-Oeste \\
\hline $\begin{array}{l}\text { Sofrimento da equipe } \\
\text { de saúde no contexto } \\
\text { hospitalar: cuidando do } \\
\text { cuidador profissional. }\end{array}$ & Lilacs & $\begin{array}{c}\text { Revisão } \\
\text { de } \\
\text { literatura }\end{array}$ & $\begin{array}{c}\text { Profissionais } \\
\text { de } \\
\text { enfermagem }\end{array}$ & $\begin{array}{l}\text { mundo da } \\
\text { saúde }\end{array}$ & 2010 & Sudeste \\
\hline $\begin{array}{c}\text { Vivência dos } \\
\text { enfermeiros de unidade } \\
\text { de terapia intensiva } \\
\text { frente à morte e o } \\
\text { morrer }\end{array}$ & Lilacs & $\begin{array}{c}\text { Pesquisa } \\
\text { de } \\
\text { campo }\end{array}$ & $\begin{array}{l}\text { Profissionais } \\
\text { de } \\
\text { enfermagem }\end{array}$ & $\begin{array}{c}\text { Revista } \\
\text { Gaúcha } \\
\text { Enfermagem }\end{array}$ & 2009 & Sul \\
\hline
\end{tabular}

Fonte: Elaborado pelas próprias autoras 2012. 